\title{
Article \\ Mechanical Properties of Roof Rocks under Superimposed Static and Dynamic Loads with Medium Strain Rates in Coal Mines
}

\author{
Kun Zhong ${ }^{1,2}$, Wusheng Zhao ${ }^{1, *}$, Changkun Qin ${ }^{1,2}$, Hou Gao ${ }^{1,2}$ and Weizhong Chen ${ }^{1}$ \\ 1 State Key Laboratory of Geomechanics and Geotechnical Engineering, Institute of Rock and Soil Mechanics, \\ Chinese Academy of Sciences, Wuhan 430071, China; zhongkun17@mails.ucas.edu.cn (K.Z.); \\ ckqin_whrsm@163.com (C.Q.); gaoohouu@foxmail.com (H.G.); wzchen@whrsm.ac.cn (W.C.) \\ 2 University of Chinese Academy of Sciences, Beijing 100049, China \\ * Correspondence: wszhao@whrsm.ac.cn; Tel.: +86-027-8719-8211
}

Citation: Zhong, K.; Zhao, W.; Qin, C.; Gao, H.; Chen, W. Mechanical Properties of Roof Rocks under Superimposed Static and Dynamic Loads with Medium Strain Rates in Coal Mines. Appl. Sci. 2021, 11, 8973. https://doi.org/10.3390/app11198973

Academic Editors: Pietro Mosca, Sabrina Bonetto and Chiara Caselle

Received: 30 August 2021

Accepted: 24 September 2021

Published: 26 September 2021

Publisher's Note: MDPI stays neutral with regard to jurisdictional claims in published maps and institutional affiliations.

Copyright: () 2021 by the authors. Licensee MDPI, Basel, Switzerland. This article is an open access article distributed under the terms and conditions of the Creative Commons Attribution (CC BY) license (https:// creativecommons.org/licenses/by/ $4.0 /)$.

\begin{abstract}
Roof rocks in coal mines are subjected to the combination of in situ stresses and dynamic stresses induced by mining activities. Understanding the mechanical properties of roof rocks under static and dynamic loads at medium strain rates is of great significance to revealing the mechanism of rock bursts. In this study, we employ the digital image correlation (DIC) technique to investigate the energy concentration and dissipation behaviors, failure mode, and deformation characteristics of roof rocks under combined static and dynamic loads. Our results show that both the static pre-stress and dynamic loading rate have significant effects on the uniaxial compressive strength of rock specimens. From the energy principle, when the static pre-stress is the same, both elastic strain energy density and dissipated energy density increase with increasing dynamic loading rate. The hazard of rock bursts increases with decreasing static pre-stress and increasing dynamic loading rate. At higher dynamic loading rates, more cracks are generated, and the failure becomes more violent. The crack initiation, propagation and coalescence processes are identified, and the failure mode is closely related to the evolution of the global principal strain field of the rock specimens.
\end{abstract}

Keywords: static pre-stress; dynamic loading rate; strength; failure mode; energy density; principal strain field; rock bursts

\section{Introduction}

Rock bursts have become more and more severe and occurred frequently with the increase in mining depth over the years at the rate of 10-25 m per year, and a growing number of mines reach a depth of $1000 \mathrm{~m}[1,2]$. The deep coal extraction is facing stress concentration with acute occurrence and frequency of rock burst incidents induced by dynamic loads in coal mines. A large number of case studies of rock bursts are documented in America [3,4], Australia [5], Poland [6,7], Russia [8], Czech Republic [9,10] and many other countries. In China, nearly 300 coal mines have reported rock burst disasters so far, and the number is increasing [11]. Table 1 lists the major cases of rock burst disasters that occurred in China in the past five years. This table clearly reveals one common characteristic among the causes of rock bursts: stress concentration and dynamic load disturbance. Stresses in coal mines include initial stress and mining-induced stress [12], and the local concentrated high stress is the internal cause of rock bursts. Dynamic loads are mainly caused by drilling, strata fracturing, fault reactivation, coal pillar collapse and other mining and excavating-related activities [13-18]. Dynamic load disturbance and loading are the external causes of rock bursts. The superimposed static and dynamic loads are the fundamental reason for rock bursts $[19,20]$. 
Table 1. Major rock burst disasters occurred in China the past five years.

\begin{tabular}{|c|c|c|c|c|}
\hline Date & Mine & Accident Area & $\begin{array}{l}\text { Casualties and Property } \\
\text { Losses }\end{array}$ & $\begin{array}{l}\text { Direct Cause of the } \\
\text { Accident }\end{array}$ \\
\hline 17 January 2017 & $\begin{array}{l}\text { Danshuigou coal industry } \\
\text { co., ltd (Shuozhou City, } \\
\text { Shanxi Province, China) }\end{array}$ & $\begin{array}{l}\text { Headgate of } 4203 \text { fully } \\
\text { mechanized working face }\end{array}$ & $\begin{array}{l}\text { Ten fatalities and loss of } \\
15.2 \text { million RMB }\end{array}$ & $\begin{array}{l}\text { Roadway roof collapsed, } \\
\text { and the rock burst was } \\
\text { caused by mining-induced } \\
\text { stress }\end{array}$ \\
\hline 11 November 2017 & $\begin{array}{l}\text { Hongyang No.3 Mine } \\
\text { (Shenyang City, Liaoning } \\
\text { Province, China) }\end{array}$ & $\begin{array}{l}\text { Headgate of } 702 \text { fully } \\
\text { mechanized working face }\end{array}$ & $\begin{array}{l}\text { Ten fatalities and loss of } \\
14.5 \text { million RMB }\end{array}$ & $\begin{array}{l}\text { High in situ stress; stress } \\
\text { concentration area was } \\
\text { formed by the } \\
\text { combination of faults, coal } \\
\text { pillars and mining stresses; } \\
\text { rock burst was caused by } \\
\text { dynamic load disturbance } \\
\text { such as fault cutting }\end{array}$ \\
\hline 12 October 2018 & $\begin{array}{l}\text { Longyun coal industry co., } \\
\text { ltd (Heze City, Shandong } \\
\text { Province, China) }\end{array}$ & $\begin{array}{c}\text { Drainage lane and No.3 } \\
\text { contact lane in } 1303 \\
\text { working face }\end{array}$ & $\begin{array}{l}\text { Twenty-one fatalities and } \\
\text { loss of } 56.4 \text { million RMB }\end{array}$ & $\begin{array}{c}\text { High in situ stress; high } \\
\text { stress concentration area; } \\
\text { the disturbance of } \\
\text { pressure relief borehole } \\
\text { during construction and } \\
\text { disturbance of nearby } \\
\text { fault }\end{array}$ \\
\hline 9 June 2019 & $\begin{array}{l}\text { Longjiabao coal industry } \\
\text { co., ltd (Changchun City, } \\
\text { Jilin Province, China) }\end{array}$ & $\begin{array}{l}\text { Headgate of } 305 \text { fully } \\
\text { mechanized working face }\end{array}$ & $\begin{array}{l}\text { Nine fatalities and loss of } \\
19.1 \text { million RMB }\end{array}$ & $\begin{array}{l}\text { High in situ stress, high } \\
\text { horizontal tectonic stress; } \\
\text { increased regional stress } \\
\text { due to mining activities; } \\
\text { mining induced fault } \\
\text { reactivation }\end{array}$ \\
\hline 2 August 2019 & $\begin{array}{l}\text { Kailuan co., ltd. Tangshan } \\
\text { mining industry branch } \\
\text { (Tangshan City, Hebei } \\
\text { Province, China) }\end{array}$ & $\begin{array}{l}\text { F5010 connecting lane and } \\
\text { F5009 conveying lane }\end{array}$ & $\begin{array}{l}\text { Seven fatalities and loss of } \\
6.1 \text { million RMB }\end{array}$ & $\begin{array}{c}\text { High tectonic stress; } \\
\text { peninsula-shaped coal } \\
\text { pillar with highly } \\
\text { concentrated stress; } \\
\text { superimposed abutment } \\
\text { stress, high concentration } \\
\text { of mining-induced stress; } \\
\text { disturbance due to mining } \\
\text { activities }\end{array}$ \\
\hline 22 February 2020 & $\begin{array}{l}\text { Xin julong energy co., ltd } \\
\text { (Heze City, Shandong } \\
\text { Province, China) }\end{array}$ & $\begin{array}{l}\text { Upper passageway of } \\
\text { 2305S fully mechanized } \\
\text { working face }\end{array}$ & $\begin{array}{c}\text { four fatalities and loss of } \\
18.5 \text { million RMB }\end{array}$ & $\begin{array}{l}\text { Large-scale overhang roof } \\
\text { caused local high stress } \\
\text { concentration; mining } \\
\text { disturbance on the } \\
\text { working face induced } \\
\text { fault slip in the wedge } \\
\text { graben area }\end{array}$ \\
\hline
\end{tabular}

The coal mines affected by hard and thick roofs account for more than $50 \%$ of the mining areas, and the hard roof is one of the leading causes for rock bursts [21,22]. Hard roof rocks generally have high strength and low probability of caving. However, with the continuous advance of the mining face and the increasing overhang area, the hanging roof could collapse, causing seismic waves [23-25] to propagate in the form of dynamic loads. Once the shock wave propagates to the static loading area, this leads to the superimposition of static and dynamic loads. Therefore, the deformation and failure of thick and hard roofs in coal mines are not only affected by the static in situ stress, but also the dynamic loading rate caused by mining activities. Especially, the failure of roof and coal pillars due to dynamic loading rate becomes more critical as the mining depth increases and mining activities intensify. Therefore, when the rock failure cannot be explained solely by static or dynamic theory [26], it is crucial to consider the combination of static in situ stress and dynamic loading rate to understand the mechanical behavior and failure characteristics of roof rocks [27].

To date, no consensus understanding exists regarding the cutoff between static and dynamic loading rates. The concept of static and dynamic loads is not definite, and is closely related to material types and the environment [28]. The relationship between the dynamic strain rate and seismic wave parameters in coal mines was obtained through an in situ test [29]. Unlike explosions, air blasts, dynamic compaction, piling and rapid loading tests, the maximum dynamic strain rate in coal mines ranges from $10^{-3}$ to $10^{-1} \mathrm{~s}^{-1}$, which is a medium strain rate range [30]. Therefore, the analysis of the mechanical behaviors of rock at medium strain rates is of great significance to mine earthquakes, rock bursts and coal 
bumps. However, most of the superimposed static and dynamic loading tests are generally performed by using the split Hopkinson pressure bar (SHPB) [31-34], which is suitable for higher strain rates surpassing $10^{1} \mathrm{~s}^{-1}$ [35]. As a result, the superimposed static and dynamic tests on rock specimens using the servo-controlled rock mechanical test system (MTS) may be more in line with the actual situation in coal mines. Recently, laboratory experiments were conducted to understand the mechanical properties of rock specimens in coal mines under superimposed static and dynamic loads, and the characteristics of the stress-strain curve, mechanical parameters and failure patterns have been presented [36]. For instance, Lyu et al. [37] carried out uniaxial coupled statics and dynamics tests and acquired rock burst tendency of coal, the AE parameters, the failure mode and the fracture morphology. Zhao et al. [38] conducted tests on coal specimens under different medium strain rates and proposed an empirical relationship between the peak strength and the strain rate; they also found that the evolution and distribution of stress and deformation were affected by the heterogeneity of the specimens. Liang et al. [39] systematically studied the failure process, fracture characteristics, and failure micro-mechanism of rock at low and medium strain rates for $10^{-5}-10^{-1} \mathrm{~s}^{-1}$, and a good correlation between the failure and strain rates had been found. In general, there are few experimental studies focusing on the combination of dynamic and static loads on coal and rock under realistic stress conditions for coal mines.

Rock failure is the result of initiation, propagation and coalescence of internal cracks under loading. The understanding of fracture and deformation evolution of specimens is of importance to describe the damage and failure process of rock materials [40]. Many scholars have applied a variety of measurement methods to investigate the fracture evolution, such as scanning electron microscope (SEM) [41], X-ray computed tomography (CT) [42] and electromagnetic radiation (EMR) [43]. In most cases, rock instability and failure are caused by the development of deformation localization [44]. Therefore, the digital image correlation (DIC) technique has been used to study the deformation localization of rock specimens. As a non-contact optical method, the DIC technique can directly give fullfield displacement and calculate the strain on a specimen surface. The DIC technique has been widely used in laboratory tests because of its advantages of real time, covering full-field, online and flexibility. Li et al. [45] investigated the failure mechanisms of rock specimens with flaws under superimposed static and dynamic loads by using a modified SHPB device, and the cracking process was record in real time by DIC technique. Similarly, Lin et al. [46] used the DIC technique to investigate the fracture process of a sandstone under three-point bending with a variety of notch positions. Dong et al. [47] also employed the DIC technique to study the crack propagation process of rock-concrete interfaces under three-point bending. Most of the studies were conducted based on either static or dynamic loading condition. However, few studies have investigated failure characteristics, damage monitoring and precursor identification recognition of roof rocks under superimposed static and dynamic loading conditions.

In this study, we carry out superimposed static and dynamic loading tests at medium strain rates on roof rocks from the Zhaolou coal mine, Shandong Province, China. We apply the DIC technique to capture a range of failure patterns in specimens under superimposed static and dynamic loads. We analyze the mechanical and energy concentration, dissipation behavior and explore the damage evolution and crack propagation process based on the global strain field collected by the DIC technique.

\section{Superimposed Static and Dynamic Loading Experiments}

\subsection{Experimental Apparaturs and Loading Scheme}

Rock samples were taken from the roof layer above the \#3 coal seam at the Zhaolou Coal Mine, Shandong Province, China. The roof rock is grayish white medium-fine sandstone, which is mainly composed of quartz and contains a large amount of mica fragments. The middle part is sandwiched with thin layers of medium sandstone, and the grain size becomes coarser from top to bottom. The lower part is sandwiched with thin layers of fine 
siltstones interbedded with each other, with nearly horizontal bedding. The rock hardness coefficient $f$ is $6-7$. The samples were sliced and polished into standard specimens in shape with a diameter of $25 \mathrm{~mm}$ and a height of $50 \mathrm{~mm}$ according to the International Society for Rock Mechanics (ISRM).

The experimental apparatus mainly consists of an RMT-201 servo control testing system and a DIC observation system (Figure 1). As shown in Figure 1b, linear variable different transformers (LVDT) were used in the RMT-201 to measure the axial and lateral deformation. As shown in Figure 1c, the DIC observation system consists of industrial cameras, light sources, a data acquisition instrument and a DIC control software. Two high-speed cameras are used to continuously record the images of the specimen surface and the data acquisition instrument, and the highest shooting rate is more than 10,000 pictures per second. Two GT3400 cameras were used in this study (the resolution is $3384 \times 2074$, lens focal length is $80 \mathrm{~mm}$ ). In one direction, each speckle occupies about 3-5 pixels, subset size is 29 pixels and step size is 4 pixels. The overall score is 0.010 of the calibration result as shown in the bottom image. An optimum matching algorithm (e.g., Newton-Ralphson) matching the correlation function and sub-pixel algorithms ( 0.01 pixel) were used. We used the standard cross-correlation function, and the correlation coefficient was larger than 0.95 , close to 1 . Practice showed that the system has high accuracy, and the accuracy reached 0.01 pixels. The random trigger mode was used to take photos in the static loading stage; each time the trigger button is pressed, the left and right cameras take a picture. The start trigger mode was used to take photos in the dynamic loading stage. The DIC control software was Vic-3D, which can be used to calculate the full deformation field evolution and strain field evolution, and can be used for localized deformation analysis of specimens with various loading conditions.

According to He et al. [29], a loading process with a strain rate lower than $10^{-5} \mathrm{~s}^{-1}$ is considered a static loading condition, and that with a strain rate higher than $10^{-3} \mathrm{~s}^{-1}$ is considered dynamic loading condition. Therefore, we applied the dynamic and static loads in this study as follows: the uniaxial compressive strength (UCS) of rock specimens was obtained first under uniaxial static loading condition, the range of the UCS is $71.3-81.5 \mathrm{MPa}$ by repeated experiments, and the result of the average UCS is 77.1 MPa. This result served as a parameter basis for applying static pre-stress in superimposed static and dynamic loads. Figure 2 shows the loading path for the combined dynamic and static loading experiments. We found that the stress concentration in coal and rock mass is large in the process of coal mining, when the working face is about $11 \mathrm{~m}$ away from the monitoring section, the maximum stress is close to $60 \mathrm{MPa}$ [48]. Based on the data, four static pre-stresses (30.84, $38.55,46.26$ and $53.97 \mathrm{MPa}$ ) were considered, accounting for $40 \%, 50 \%, 60 \%$ and $70 \%$ of the UCS, respectively. The specimens were loaded in a displacement control mode, and the strain rate was controlled at $5 \times 10^{-6} \mathrm{~s}^{-1}$ for static pre-stress until the axial stress reached the target value. The dynamic load was then applied to the specimens at four different strain rates, including $2 \times 10^{-4}, 2 \times 10^{-3}, 1 \times 10^{-2}$ and $2 \times 10^{-2} \mathrm{~s}^{-1}$. The selected strain rates used in this study vary from $10^{-4}$ to $10^{-2} \mathrm{~s}^{-1}$, covering the dynamic strain rate range of micro-seismic events and rock burst accidents in coal mines [30]. In addition, we noted that the maximum strain rate of the dynamic load is at class $10^{-3}-10^{-1} \mathrm{~s}^{-1}$, which belongs to a medium strain rate range. This value will be smaller considering the attenuated shock wave; therefore, it is also appropriate to apply the corresponding strain rate directly to the small specimen of $25 \mathrm{~mm}$ in diameter and $50 \mathrm{~mm}$ in length. Table 2 lists the 16 tests conducted in this study. 


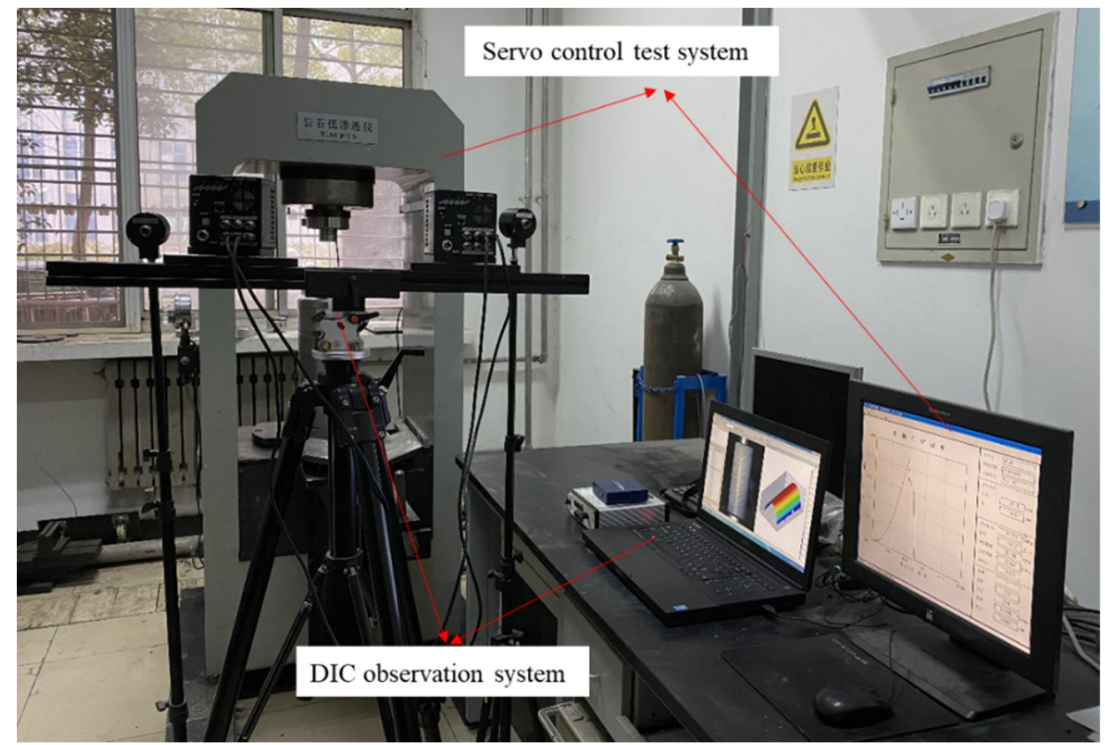

(a)

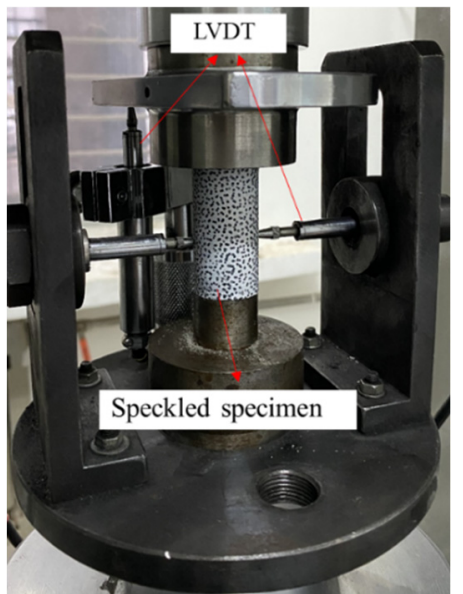

(b)

Industrial cameras

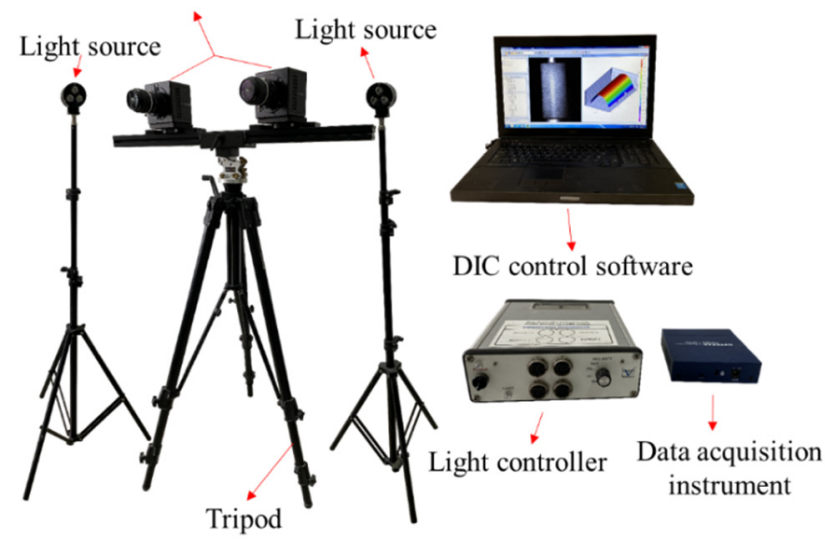

(c)

Figure 1. Superimposed static and dynamic loading experimental system: (a) full view; (b) speckled specimens and loading machine; and (c) the DIC observation system.

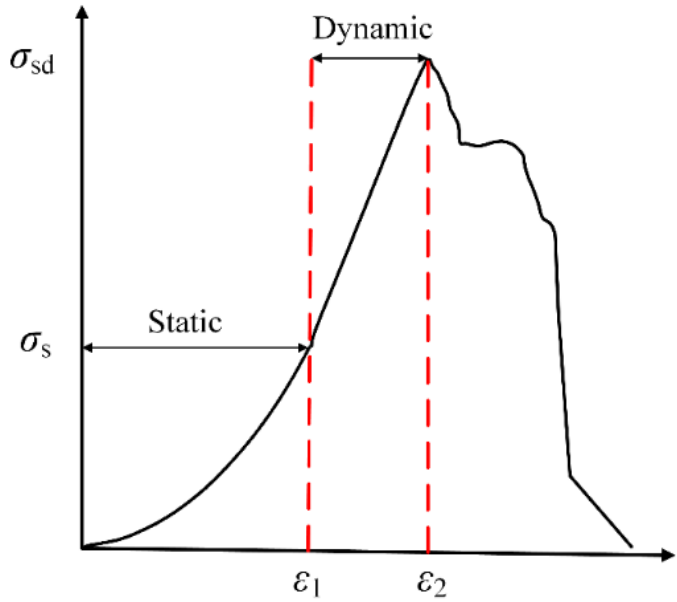

Figure 2. The scheme for the loading path of superimposed static and dynamic loads: $\sigma_{\mathrm{S}}$ represents the applied static pre-stress and $\sigma_{\text {sd }}$ represents the superimposed strength of the specimen. 
Table 2. Loading schemes.

\begin{tabular}{cccc}
\hline Test Case & $\begin{array}{c}\text { Ratio of Static } \\
\text { Pre-Stress to UCS }\end{array}$ & $\begin{array}{c}\text { Static } \\
\text { Pre-Stress/MPa }\end{array}$ & $\begin{array}{c}\text { Dynamic Strain } \\
\text { Rate/s } \mathbf{s}^{-1}\end{array}$ \\
\hline D1 & $40 \%$ & 30.84 & \\
D2 & $50 \%$ & 38.55 & $2 \times 10^{-4}$ \\
D3 & $60 \%$ & 46.26 & \\
D4 & $70 \%$ & 53.97 & $2 \times 10^{-3}$ \\
D5 & $40 \%$ & 30.84 & \\
D6 & $50 \%$ & 38.55 & $1 \times 10^{-2}$ \\
D7 & $60 \%$ & 46.26 & \\
D8 & $70 \%$ & 53.97 & \\
D9 & $40 \%$ & 30.84 & $2 \times 10^{-2}$ \\
D10 & $50 \%$ & 38.55 & \\
D11 & $60 \%$ & 46.26 & \\
D12 & $70 \%$ & 53.97 & \\
D13 & $40 \%$ & 30.84 & \\
D14 & $50 \%$ & 38.55 & \\
D15 & $60 \%$ & 46.26 & \\
D16 & $70 \%$ & 53.97 & \\
\hline
\end{tabular}

\subsection{DIC Technique}

It is necessary to spray speckles on the specimen surface for the full-field strain measurement by the DIC technique. Some specimens with speckle are shown in Figure 3. These speckles are used to calculate the field of displacement and can be treated as the signatures on the surface of a specimen [49]. The displacement field and strain field of the specimen surface are obtained by the image matching techniques and registration algorithms. Figure 4 shows the basic principles of the DIC technique.

The digital speckle image before deformation is taken as the reference image, and the square area with $f_{1}(x, y)$ as the center is used as the reference subarea. Assuming that the gray level of the sub-region remains unchanged or changes linearly after the deformation, the target subarea with $f_{2}(x, y)$ as the center and with the largest correlation coefficient to the reference subarea can be found in the deformed image by searching point by point. The horizontal and vertical displacement components $u(x, y)$ and $v(x, y)$ of the calculated point are then obtained. The coordinate of any measuring point on the digital speckle image before and after deformation meets the following relationship:

$$
\left.\begin{array}{l}
f_{2}(x)=f_{1}(x)+u(x, y) \\
f_{2}(y)=f_{1}(y)+v(x, y)
\end{array}\right\}
$$

The principle of 3D-DIC is to set up two high-speed cameras or high-resolution CCD industrial cameras, which form a certain angle with each other, calibrate the dual camera system with checkerboard target or dot mark plate, then record the same scene in space synchronously by using these two cameras, and then obtain the target subarea for two images of the specimen surface by matching algorithm at the same time. Finally, according to the camera's internal and external parameters, the spatial coordinates of the surface points are calculated. As shown in the image of Figure 5, it is possible to recover the three-dimensional position of the true object points by recording simultaneous image points using two cameras $\left(C\right.$ and $\left.C^{\prime}\right)$. The $3 D$ points $Q$ and $R$ are two points on the same projection ray $(C, P)$, which proves that there are infinite $3 \mathrm{D}$ points corresponding to the image point $P$. For example, when two image points are $\left(p, q^{\prime}\right)$, the unique $3 D$ point is $Q$. If the corresponding image points are $\left(p, r^{\prime}\right)$, the unique $3 D$ point is $R$. 


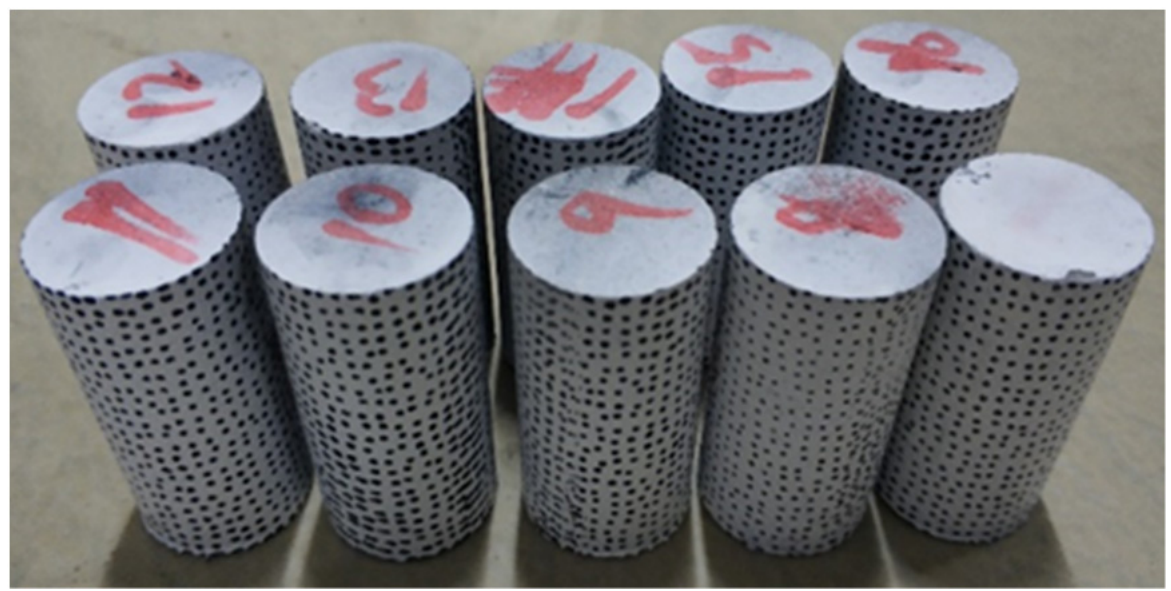

Figure 3. Specimens with speckles.

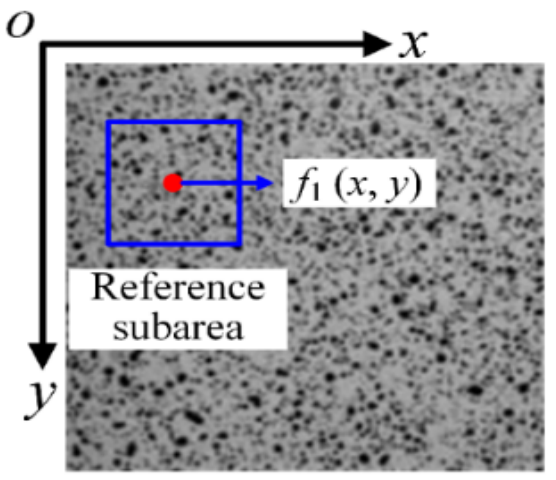

(a)

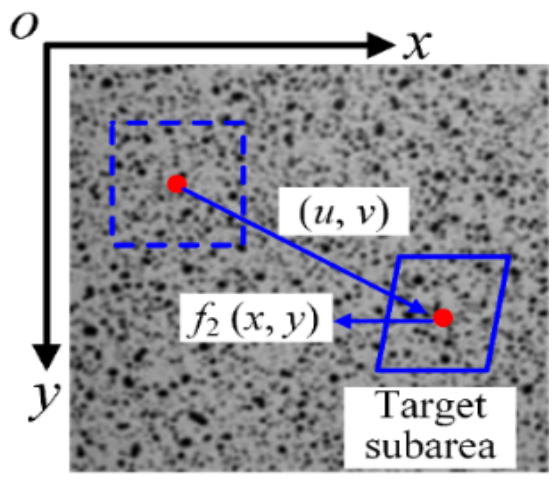

(b)

Figure 4. Sketches of correlation match: (a) reference image; (b) deformed image.

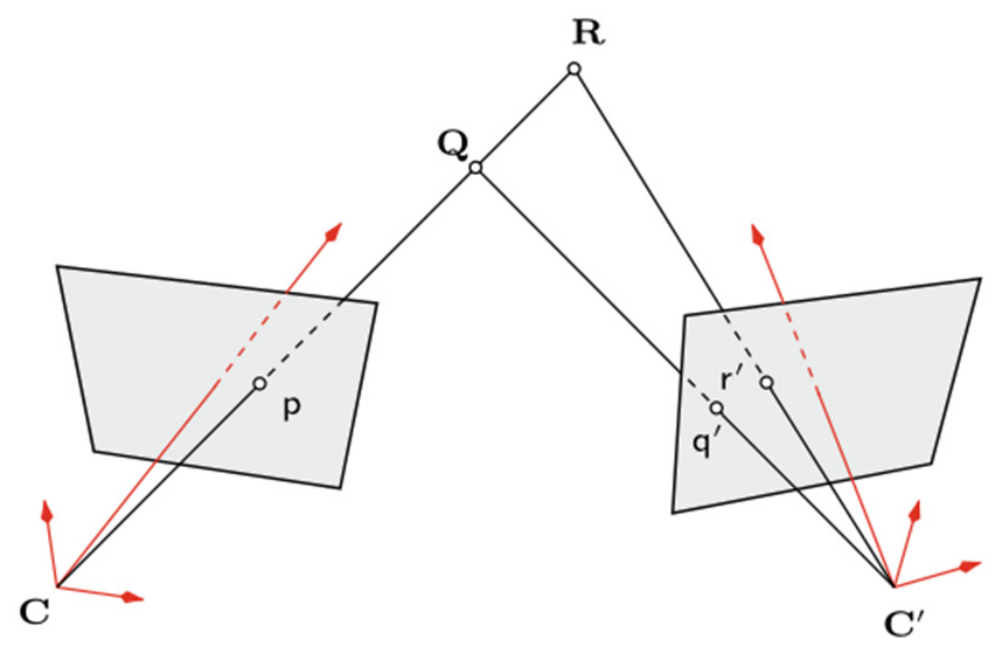

Figure 5. Recovering the third dimension by two cameras.

\section{Test Results and Discussion}

\subsection{Strength Characteristics}

3.1.1. Effect of Applied Static Pre-Stress under the Same Dynamic Loading Rate

Figure 6 shows the effect of applied static pre-stress on the superimposed uniaxial compressive strength (SUCS) and the elastic modulus of rock specimens, as detailed in Table 3. At the same dynamic loading rate, the specimens exhibit distinct mechanical 
behaviors with different static pre-stresses, as shown in Figure 6a. When the dynamic loading rate is $2 \times 10^{-4} \mathrm{~s}^{-1}$, no correlation is observed between the SUCS and the static prestress, and the SUCS remains around $80 \mathrm{MPa}$, slightly higher than the static compressive strength of $77.1 \mathrm{MPa}$. When the dynamic loading rate is increased to $2 \times 10^{-3} \mathrm{~s}^{-1}$, the SUCS and static pre-stress begin to show a clear linear relationship, which can be expressed as:

$$
S_{1}=-49.34 R+112.4595
$$

where $S_{1}$ is the SUCS when the dynamic loading rate is $2 \times 10^{-3} \mathrm{~s}^{-1}$, and $R$ is the ratio of static pre-stress to the UCS. The SUCS decreases from 92.53 to $77.62 \mathrm{MPa}$ when the static pre-stress increases from $40 \%$ of the UCS to $70 \%$ of the UCS. For dynamic loading rates of $1 \times 10^{-2} \mathrm{~s}^{-1}$ and $2 \times 10^{-2} \mathrm{~s}^{-1}$, a similar relationship between the SUCS and applied static pre-stress can be written as:

$$
\begin{aligned}
& S_{2}=-83.37 R+134.7045 \\
& S_{3}=-83.37 R+134.7045
\end{aligned}
$$

where $S_{2}$ and $S_{3}$ are the SUCS when the dynamic loading rates are $1 \times 10^{-2}$ and $2 \times 10^{-2} \mathrm{~s}^{-1}$, respectively, and $R$ is the ratio of static pre-stress to the UCS. The higher the dynamic loading rate, the larger the difference in SUCS under different static pre-stresses. As shown in Figure 6, the SUCS is decreased from 103.25 to $77 \mathrm{MPa}$ at a dynamic loading rate of $1 \times 10^{-2} \mathrm{~s}^{-1}$ and decreases from 107.82 to $81.90 \mathrm{MPa}$ for the dynamic loading rate of $2 \times 10^{-2} \mathrm{~s}^{-1}$. These results may be explained as follows. When the dynamic loading rate is below $10^{-3} \mathrm{~s}^{-1}$, the SUCS exhibits a weak rate dependence, similar to the pure static loading condition, so the SUCS remains nearly stable as the static pre-stress changes. The magnitude of the SUCS change increases under different static pre-stresses as the dynamic loading rate increases, as evidenced by the steeper fitting line in Figure 6 . In addition, the lower the static pre-stress, the greater the contribution of the dynamic loading rate, and the larger the SUCS.

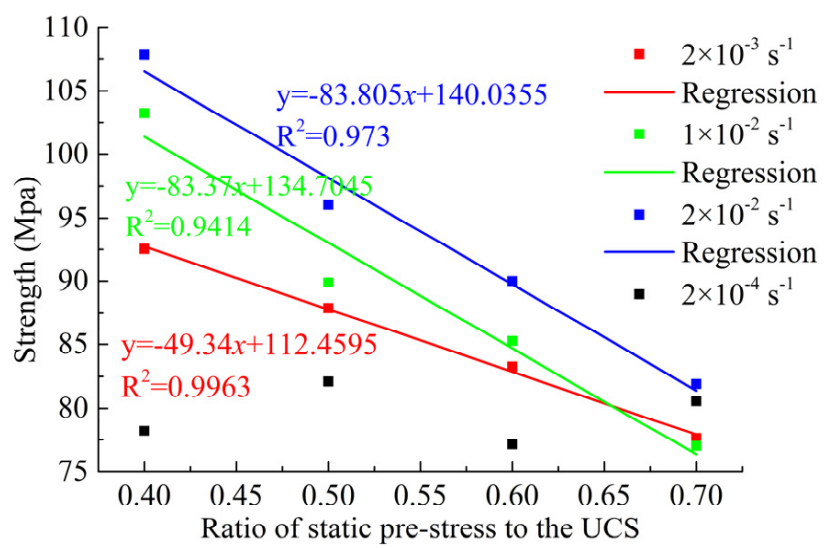

(a)

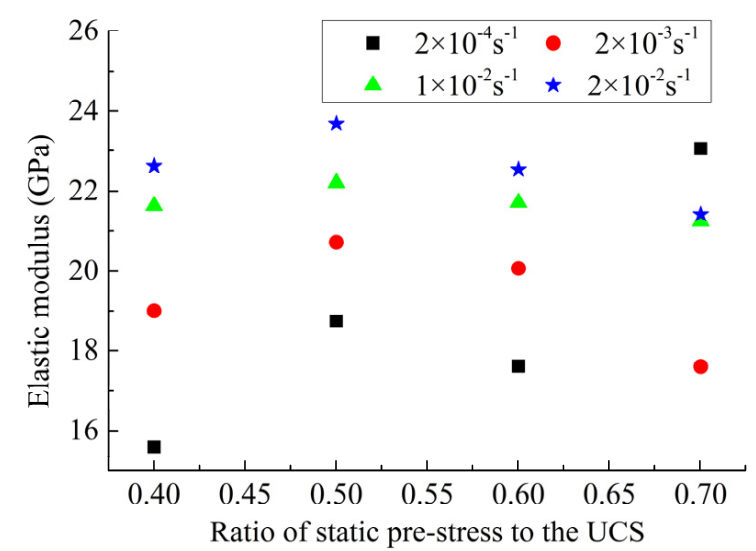

(b)

Figure 6. The (a) strength and the (b) elastic modulus influenced by the static pre-stress.

At the same dynamic loading rate, the elastic modulus reaches the peak when the static pre-stress is $50 \%$ of the UCS. When static pre-stress is increased from $40 \%$ of the UCS to $50 \%$ of the UCS, the specimens are more compressed and some of the pre-existing cracks and micro-pores in the specimens are further closed, leading to the increment in elastic modulus. However, when the static stress is increased from $50 \%$ of the UCS to $70 \%$ of the UCS, the effect of static pre-stress on the elastic modulus becomes negligible. In addition, the higher the static pre-stress, the weaker the effect of the dynamic loading strain rate on the elastic modulus. Therefore, the elastic modulus increases first and then decreases with increasing static pre-stress. 
Table 3. The experimental results of superimposed static and dynamic loading rates.

\begin{tabular}{|c|c|c|c|c|c|c|c|}
\hline Test Case & $\begin{array}{c}\text { Static } \\
\text { Stress/MPa }\end{array}$ & $\begin{array}{l}\text { Dynamic } \\
\text { Strain } \\
{\text { Rate } / s^{-1}}^{-1}\end{array}$ & SUCS/MPa & $\begin{array}{c}\text { Elastic Mod- } \\
\text { ulus/GPa }\end{array}$ & $\mathrm{Ue} /\left(\mathrm{kJ} / \mathrm{m}^{3}\right)$ & $\mathrm{Ud} /\left(\mathbf{k J} / \mathrm{m}^{3}\right)$ & $\mathrm{U} /\left(\mathbf{k J} / \mathrm{m}^{3}\right)$ \\
\hline D1 & 30.84 & $2 \times 10^{-4}$ & 78.20 & 15.59 & 196.2 & 88.9 & 285.1 \\
\hline D2 & 38.55 & $2 \times 10^{-4}$ & 82.10 & 18.74 & 179.8 & 40.3 & 220.1 \\
\hline D3 & 46.26 & $2 \times 10^{-4}$ & 77.13 & 17.62 & 168.8 & 78.1 & 246.9 \\
\hline D4 & 53.97 & $2 \times 10^{-4}$ & 80.57 & 23.05 & 140.8 & 101.3 & 242.1 \\
\hline D5 & 30.84 & $2 \times 10^{-3}$ & 92.53 & 19.00 & 225.3 & 43.3 & 268.6 \\
\hline D6 & 38.55 & $2 \times 10^{-3}$ & 87.88 & 20.72 & 186.4 & 32.3 & 218.7 \\
\hline D7 & 46.26 & $2 \times 10^{-3}$ & 83.26 & 20.07 & 172.7 & 86.6 & 259.3 \\
\hline D8 & 53.97 & $2 \times 10^{-3}$ & 77.62 & 17.61 & 171.1 & 156.4 & 327.5 \\
\hline D9 & 30.84 & $1 \times 10^{-2}$ & 103.25 & 21.63 & 246.4 & 73.6 & 320.0 \\
\hline D10 & 38.55 & $1 \times 10^{-2}$ & 89.89 & 22.2 & 182.0 & 60.9 & 242.9 \\
\hline D11 & 46.26 & $1 \times 10^{-2}$ & 85.63 & 21.71 & 168.8 & 162.6 & 331.4 \\
\hline D12 & 53.97 & $1 \times 10^{-2}$ & 77.00 & 21.24 & 139.6 & 101.2 & 240.8 \\
\hline D13 & 30.84 & $2 \times 10^{-2}$ & 107.82 & 22.62 & 257.0 & 37.5 & 294.5 \\
\hline D14 & 38.55 & $2 \times 10^{-2}$ & 96.05 & 23.69 & 194.7 & 59.9 & 254.6 \\
\hline D15 & 46.26 & $2 \times 10^{-2}$ & 90.00 & 22.53 & 179.7 & 86.3 & 266.0 \\
\hline D16 & 53.97 & $2 \times 10^{-2}$ & 81.90 & 21.41 & 156.7 & 61.8 & 218.5 \\
\hline
\end{tabular}

\subsubsection{Effect of Dynamic Loading Rate under the Same Static Pre-Stress}

Figure 7 shows the effect of dynamic loading rate on the SUCS and the elastic modulus of the rock specimens. We observe different mechanical behaviors with different dynamic loading rates, and a high dependence on strain rate, as shown in Figure 7a. When the static pre-stress is at a low level; taking the $40 \%$ of the UCS as an example, the SUCS increases from 78.20 to $107.82 \mathrm{MPa}$ (an increment of 37.88\%) when the dynamic loading rate is increased from $2 \times 10^{-4}$ to $2 \times 10^{-2} \mathrm{~s}^{-1}$. We found that the logarithmic form is the most consistent when we fit the curve of the experimental data. Some scholars have conducted similar studies using other rock materials [30,37]. An increase in static pre-stress weakens the strain rate effect on the SUCS. In the case of static pre-stress equal to $50 \%$ of the UCS, the SUCS increases from 82.10 to $96.05 \mathrm{MPa}$ (an increment of $17 \%$ ) as the dynamic loading rate increases from $2 \times 10^{-4}$ to $2 \times 10^{-2} \mathrm{~s}^{-1}$. The relationship between the SUCS and the dynamic loading rate can be written as:

$$
\begin{aligned}
& S_{4}=134.04+6.7 \ln \dot{\varepsilon} \\
& S_{5}=109.07+3.7 \ln \dot{\varepsilon} \\
& S_{6}=99.85+2.8 \ln \dot{\varepsilon}
\end{aligned}
$$

where $S_{4}, S_{5}$ and $S_{6}$ are the SUCS when the static pre-stresses are $40 \%$ of the UCS, $50 \%$ of the UCS and $60 \%$ of the UCS, respectively, and $\dot{\varepsilon}$ is the dynamic loading rate. When the static pre-stress is furthered increased to 0.7UCS, the SUCS does not increase with increasing dynamic loading rate. The laboratory test results indicate that the dynamic loading rate plays a major role in the SUCS at low static pre-stress (less than $40-50 \%$ of the UCS), and the SUCS increases significantly with increasing dynamic loading rate. At medium static pre-stress (50-60\% of the UCS), both static pre-stress and dynamic loading rate play a major role in the SUCS, and the SUCS increases with increasing dynamic loading rate, but the increased magnitude declines significantly. At high static pre-stress levels (more than $60-70 \%$ of the UCS), the SUCS is primarily dependent on static pre-stress, and has a relatively low dependency on the dynamic loading rate. 


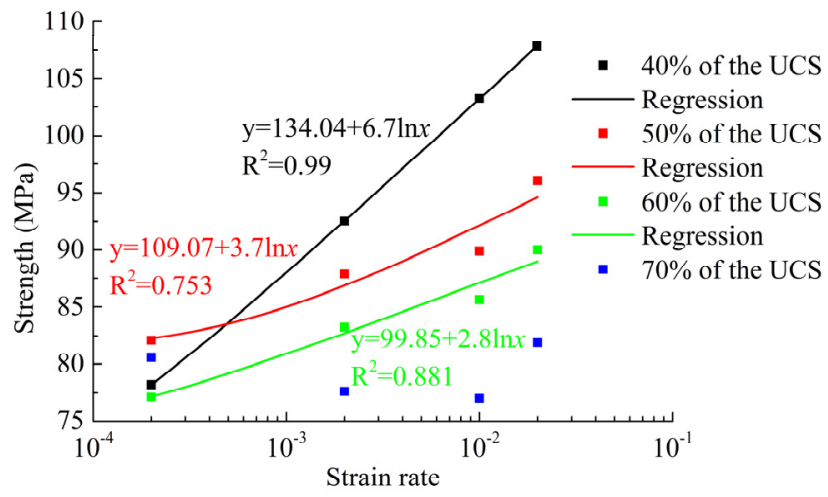

(a)

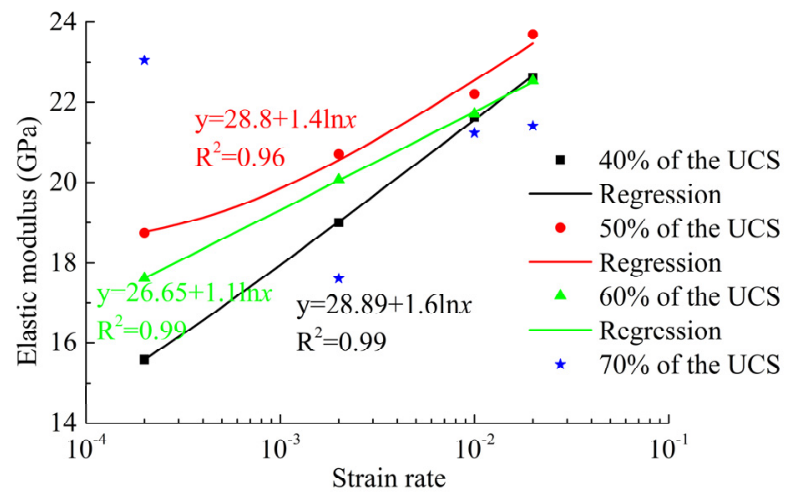

(b)

Figure 7. The (a) strength and the (b) elastic modulus influenced by the dynamic loading rate.

Under the same static pre-stress, the variation of elastic modulus with the dynamic loading rate shows a similar trend with that of the SUCS, as shown in Figure $7 \mathrm{~b}$. The relationship between the elastic modulus and the dynamic loading rate can be expressed as:

$$
\begin{aligned}
& E_{1}=28.89+1.6 \ln \dot{\varepsilon} \\
& E_{2}=28.80+1.4 \ln \dot{\varepsilon} \\
& E_{3}=26.65+1.1 \ln \dot{\varepsilon}
\end{aligned}
$$

where $E_{1}, E_{2}$ and $E_{3}$ are the elastic modulus when the static pre-stresses are $40 \%$ of the UCS, $50 \%$ of the UCS and $60 \%$ of the UCS, respectively, and $\dot{\varepsilon}$ is the dynamic loading rate.

\subsection{Energy Characteristics}

The dynamic energy release leads to some form of rock failure [50]. The deformation of rock elements under external loads can be regarded as a closed system, and as a result, the total input energy density $U$ produced by the external load can be converted into two kinds of energy [51,52]. One is the released elastic energy $U_{\mathrm{e}}$, directly related to the elastic modulus and Poisson's ratio of the rock. The release of elastic energy can cause structural failure of the specimen at the end of the loading. The other is the dissipated energy $U_{\mathrm{d}}$, manifested by the micro damage and irreversible deformation of the specimen during the loading process and accompanied by the strength deterioration [35].

Figure 8 illustrates a typical stress-strain curve and the relationship between the released elastic energy density and the dissipated energy density, which are shown in the regions of vertical lines (red) and oblique lines (yellow), respectively. Based on the two assumptions [51,52], the total energy density input from the external work can be written as:

$$
U=U_{\mathrm{e}}+U_{\mathrm{d}}=\int_{0}^{\varepsilon_{0}} \sigma d \varepsilon
$$

where $\sigma$ represents the stress and $\varepsilon$ indicates the strain of the rock specimen during the loading process; $\varepsilon_{0}$ denotes the strain value corresponding to the peak stress point.

The released elastic energy density $\left(U_{\mathrm{e}}\right)$ can be obtained as:

$$
U_{\mathrm{e}}=\sigma_{0}^{2} / 2 E
$$

where $\sigma_{0}$ represents the SUCS and $E$ represents the elastic modulus of the specimen.

Consequently, the dissipated energy density $\left(U_{\mathrm{d}}\right)$ of the specimen can be obtained as:

$$
U_{\mathrm{d}}=U-U_{\mathrm{e}}
$$


Figure 9 reveals the effect of the static pre-stress on the released elastic energy density and dissipated energy density. When the dynamic loading rate is constant, the released elastic energy density decreases linearly with increasing static pre-stress, similar to the SUCS trend. There is no clear trend between the dissipated energy density and the static pre-stress. In general, the dissipated density increases as the static pre-stress increases. Combining Figure $9 a, b$, it can be seen that when the static pre-stress is low $(40 \%$ of the UCS), the dynamic loading rate plays a major role in the energy partitioning, with high released elastic strain energy and low dissipated energy.

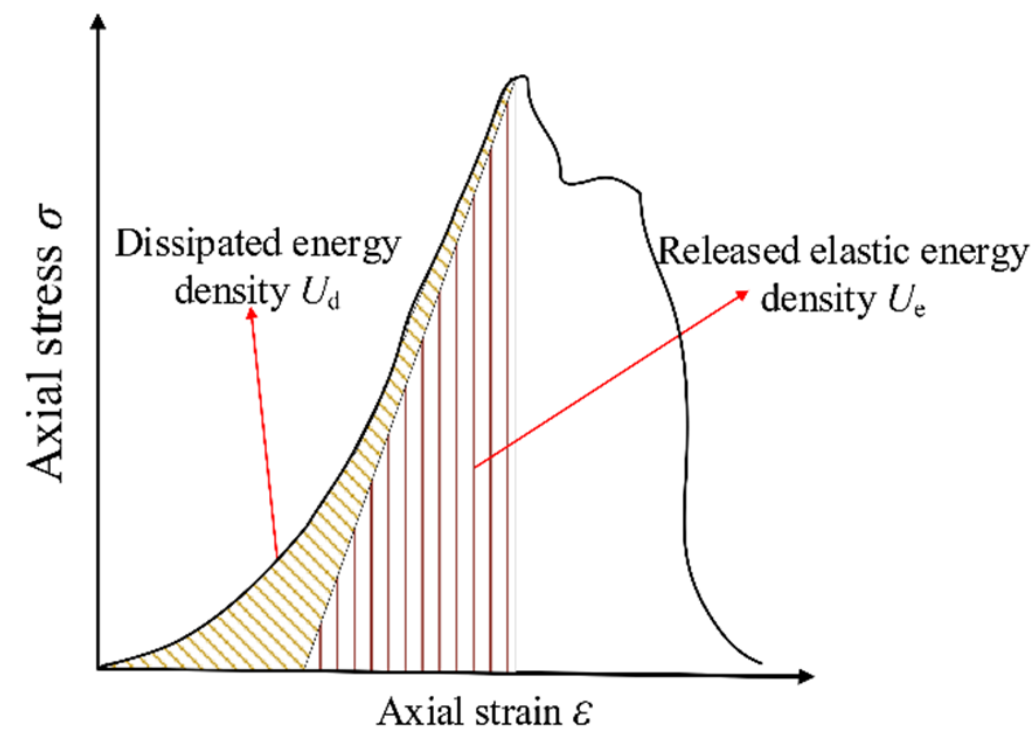

Figure 8. The relationship between the released elastic energy density and the dissipated energy density.

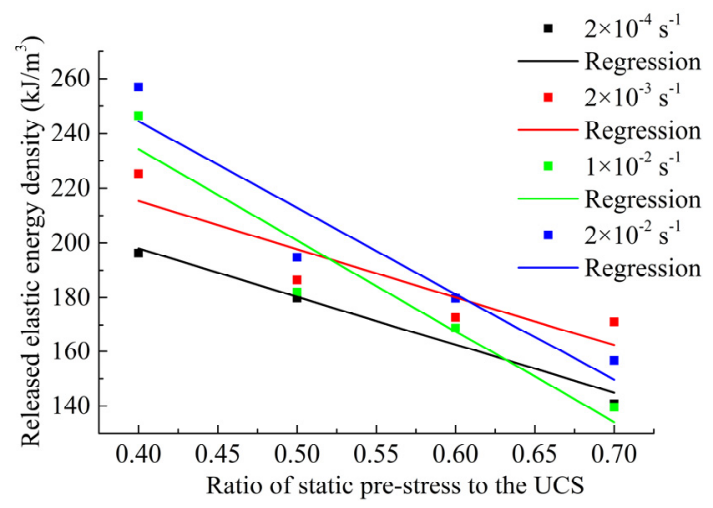

(a)

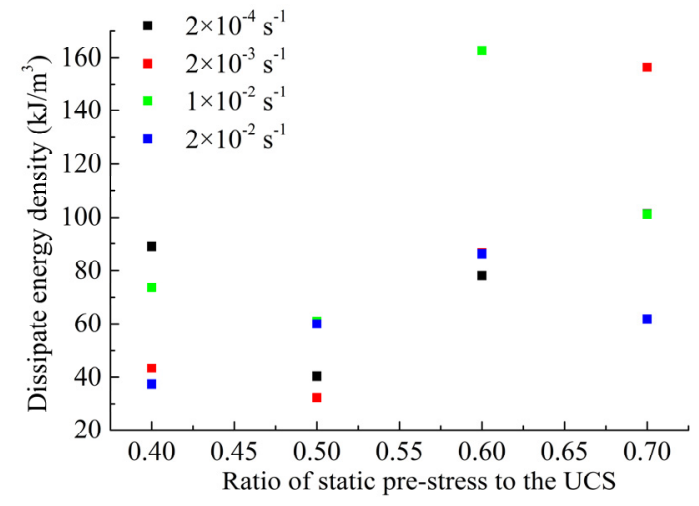

(b)

Figure 9. Effect of static pre-stress on (a) the released elastic energy density and (b) the dissipated energy density.

Figure 10 shows the effect of dynamic loading rate on the released elastic energy density and dissipated energy density. When the static pre-stress is $40 \%$ of the UCS, the released elastic energy increases logarithmically. When the static pre-stress is greater than or equal to $50 \%$ of the UCS, the logarithmic increasing function for the released elastic energy no longer exists, but a general increasing trend still holds. For the dissipated energy density, there is no direct correlation between dissipated energy density and dynamic strain rates. 


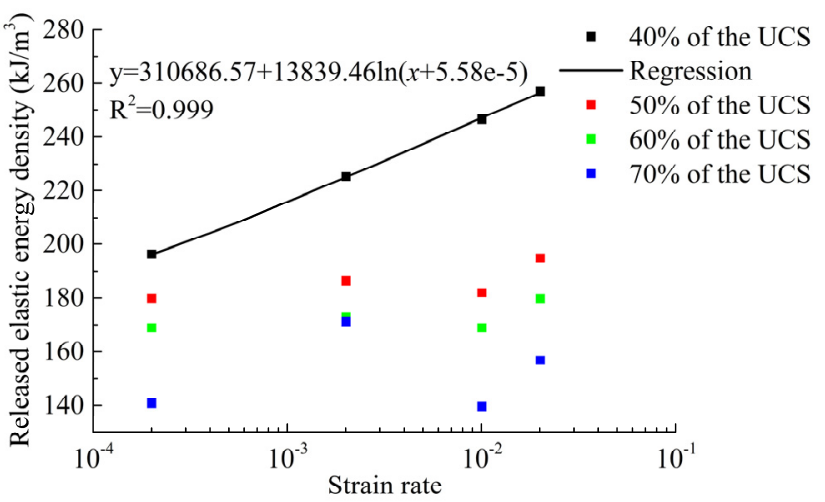

(a)

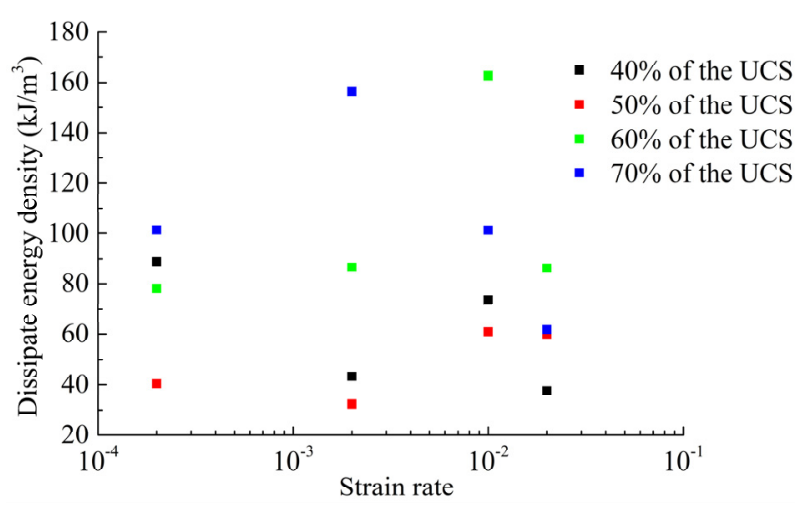

(b)

Figure 10. Effect of dynamic loading rate on (a) the released elastic energy density and (b) the dissipated energy density.

Table 3 list details of the energy characteristics of specimens under superimposed static and dynamic loads. The total input energy density $U$ varies from 218 to $330 \mathrm{~kJ} / \mathrm{m}^{3}$ under different combinations of static and dynamic loads, with an average value of $264.8 \mathrm{~kJ} / \mathrm{m}^{3}$.

\subsection{Failure Modes}

To analyze the effect of static pre-stress and dynamic loading rate on failure patterns under superimposed static and dynamic loads, some specimens were specially selected for detailed analysis. Table 4 lists the DIC results of a principal strain field (tensile strain field) corresponding to the peak stress point under superimposed static and dynamic loads, and the failure image corresponds to post-peak failure stage- that is, the time corresponding to the picture of DIC analysis is earlier than the specimen failure image. The figure of DIC analysis and figure of failure image are put together to explore the relationship between strain field evolution and specimen failure. Based on the distribution law of the strain field, combined with the final failure pattern and deformation contour, the strain field is divided into the area within a strain localization zone (plastic zone) and a non-localization zone (elastic zone) [53], with the white dashed line is the dividing line. The strain gradient in the plastic zone is large, and it is uniform in the elastic zone.

At the same static pre-stress but different dynamic loading rate, taking specimens D6 and D10 as examples, the strain localization zone and the maximum strain increase with increasing dynamic loading rate, and the specimen failure modes change from tensile-shear failure to tensile failure. When the dynamic loading rate is the same, taking specimens D6 and D8 as examples, as the static pre-stress increases, the strain localization zone and the maximum strain increase, but the failure mode does not change under the same dynamic loading rate.

The dynamic loading rate plays an important role in controlling the failure mode, while the static pre-stress applied in this study does not change the failure mode and only affects the crack width. A strong correlation exists between the failure mode and the strain rates [39]. The failure characteristics of hard roof rocks may be different from limestone [54], salt rock [55] and other "soft rocks", the failure modes of which do not change with different loading rates.

Moreover, strain localization is also an important feature that reflects the failure pattern. When the static pre-stress and dynamic loading rate are not high (specimen D6, $50 \%$ of the UCS for static pre-stress and $2 \times 10^{-3} \mathrm{~s}^{-1}$ for dynamic strain rate), the principal strain contour corresponding to the peak stress remains the same, at which point no cracks have been generated, and after the peak stress, cracks start to form. With increasing static pre-stress and dynamic loading rate, cracks begin to appear at the peak stress point, the number of cracks increases and the range of the strain localization zone increases. 
Table 4. The failure patterns of rock specimens under superimposed static and dynamic loads.

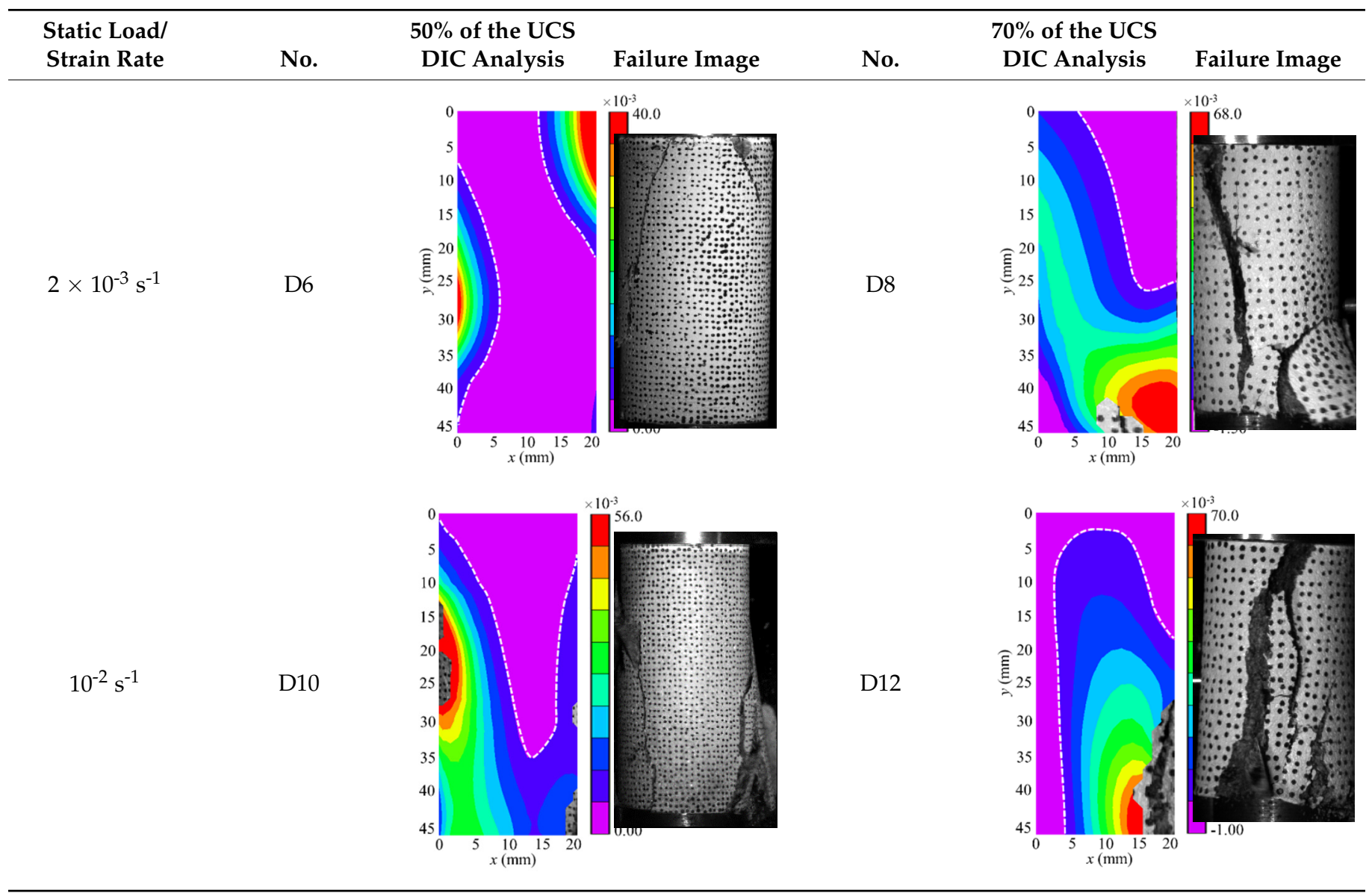

\subsection{Deformation and Cracking Process}

By observing the evolution of the strain field on the specimen surface, the strain localization and failure characteristics can be captured. Figures in Table 4 show that the strain localization zone can characterize the final crack formation area; therefore, the strain evolution process can be used to analyze the formation and propagation of cracks. The highspeed cameras of the DIC observation system are used to record the global deformation field during the static and dynamic loading stages. In this study, the strain evolution and crack propagation process are analyzed using specimens with different strain rates (D6 and D10).

\section{(1) Specimen D6}

A typical stress-strain curve with five key stress points (a-e) under superimposed static and dynamic loads is given in Figure 11. The principal strain fields are compared and analyzed at different stress stages. The stress-strain curves are consistent and can be divided into four stages: compaction, elastic deformation, pre-peak yield and postpeak failure. Point "a" is the dividing point between static loading stage and dynamic loading stage, point " $\mathrm{b}$ " belongs to elastic deformation stage, point " $\mathrm{c}$ " belongs to pre-peak yield stage, point " $\mathrm{d}$ " corresponds to the peak stress point and point " $\mathrm{e}$ " belongs to postpeak yield stage. Figure 12 shows the evolution of the principal strain field of specimen D6 at five selected stress stages. We can summarize the evolving relationship between crack propagation process and stress condition by comparing the strain results and the corresponding stress stages. 


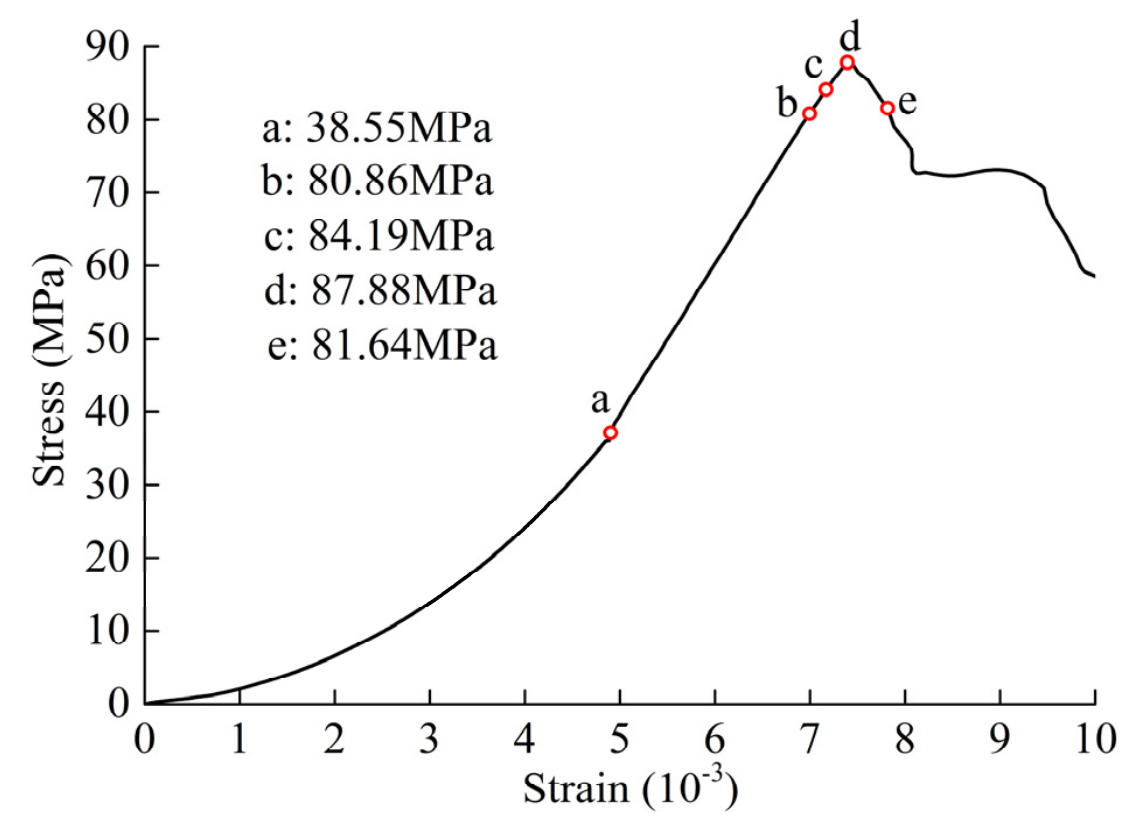

Figure 11. The stress-strain curve and key stress points of specimen D6.

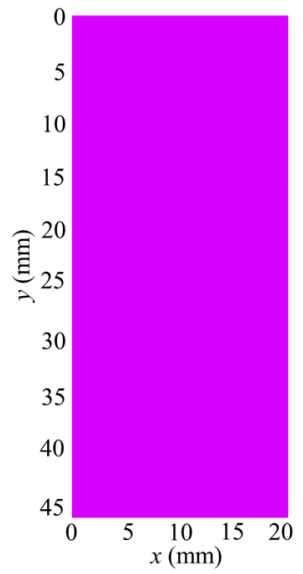

(a)

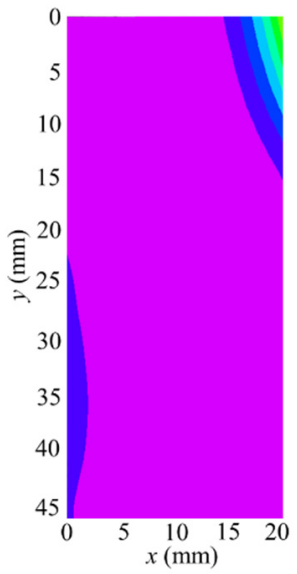

(b)

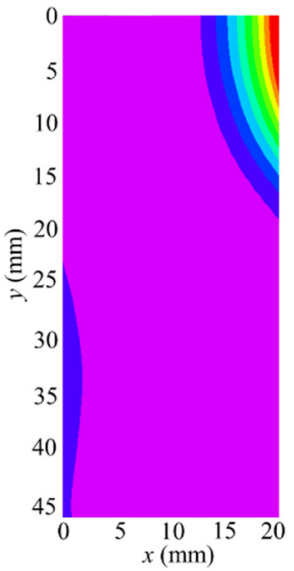

(c)

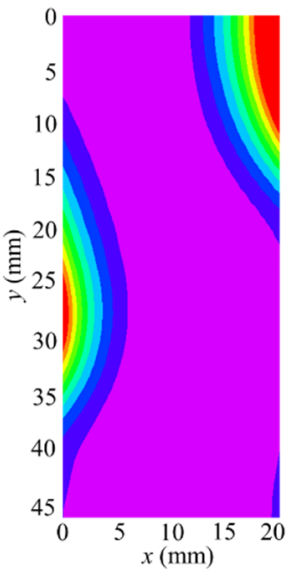

(d)

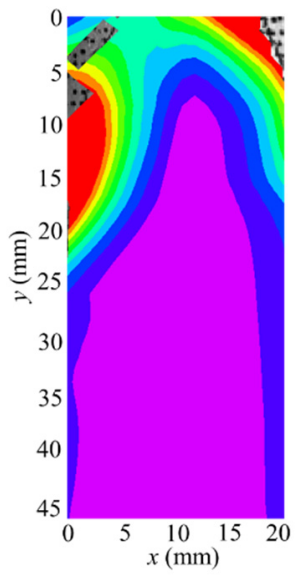

(e)

$\begin{array}{lllllllllll}0.00 & 4.00 & 8.00 & 12.0 & 16.0 & 20.0 & 24.0 & 28.0 & 32.0 & 36.0 & 40.0\end{array}$ $\times 10^{-3}$

Figure 12. The principal strain fields corresponding to point (a-e) under different loading stages in Figure 10.

During the static loading stage (stress $\leq 38.55 \mathrm{MPa}, 50 \%$ of the SUCS), the principal strain field remains uniform, after which strain localization zones (Figure 12b) begin to appear in the upper right and lower left of the specimen, indicating the development of damage. As the applied stress increases, the strain concentration area in the upper right corner of the rock specimen (Figure 12c) is further expanded, and the principal strain gradient is much larger than that in other areas. Subsequently, the stress increases to the peak stress under superimposed static and dynamic loads, and the strain localization zone (Figure 12d) is fully formed. Finally, the cracks are created quickly after the peak stress (Figure 12e), and the strain concentration area is distributed along the crack position. Figure 13 illustrates the failure process of specimen D6. The crack propagation pattern is simple; two single cracks extend rapidly, and the specimen immediately loses its carrying capacity. 


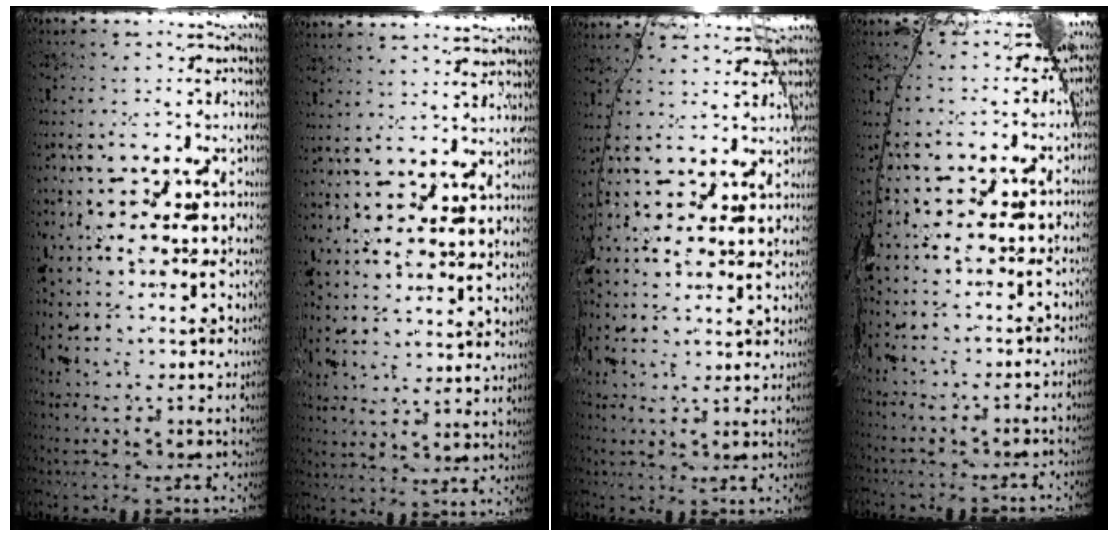

Figure 13. Image of the failure process of specimen D6.

The deformation and crack propagation process of rock specimens can be obtained by the DIC technique. It can be found from the strain distribution that the damage accumulates gradually with increasing stress, and the principal strain distribution tends to be concentrated in a narrow area at peak stress point, indicating the localization of rock damage. After the peak stress, the cracks propagate rapidly from the strain localized area to the top of the specimen, as shown in Figure 12e. We observe that the identified crack corresponds to the path of the strain localization zone. It can be concluded from the entire loading process that the damage continues to accumulate and strain before the peak stress, while cracks rapidly extend and form after the peak stress.

(2) Specimen of D10

Figure 14 illustrates the principal strain fields of specimen D10 corresponding to key points (a)-(e), shown in Figure 15. At the end of the static loading phase, the principal strain of the specimen is evenly distributed (Figure 14a). As the stress increases from point "a" to point " $b$ ", the strain localization zone (Figure 14b) appears in the lower right corner of the specimen, and the strain gradient within this region is significantly larger than that outside of this region. Subsequently, a crack appears in the lower right corner of the specimen in a short time, and another strain localization zone appears on the left side (Figure 14c). Point " $\mathrm{d}$ " corresponds to the peak stress, at which point the main crack starts to form and extends. After a sudden stress drop, the crack eventually penetrates through the specimen, almost parallel to the indentation direction. Figure $14 \mathrm{e}$ shows the strain contour at the end of fracture propagation, and the failure mode is determined.

Figure 16 illustrates the failure process of specimen D10. The initial crack appears on the surface of the specimen, accompanied by the spalling and ejection of small rock fragments from the surface. Subsequently, multiple cracks are generated and extended simultaneously. As shown in the Figure 16, there are two main cracks. The cracks continue to propagate until the rock specimen is ruptured into three parts, and the right part is quickly broken into several small pieces, resulting in disintegration and ejection.

The strain localization can better identify the crack initiation and propagation processes based on the above analysis. The formation of the strain localization zone can be considered a precursor stage of crack propagation. Comparing specimens D6 and D10 under the same static pre-stress but different dynamic loading rates, we find that both of the strain localization zones appear on the specimen surface before cracks are created, but the corresponding stress values are different. When the dynamic loading rate is $2 \times 10^{-3} \mathrm{~s}^{-1}$, the initial strain localization zone is formed at $84.19 \mathrm{MPa}(95.8 \%$ of the SUCS) while the initial strain localization zone is formed at $81.44 \mathrm{MPa}(90.6 \%$ of the SUCS) when the dynamic loading rate rises to $10^{-2} \mathrm{~s}^{-1}$. 


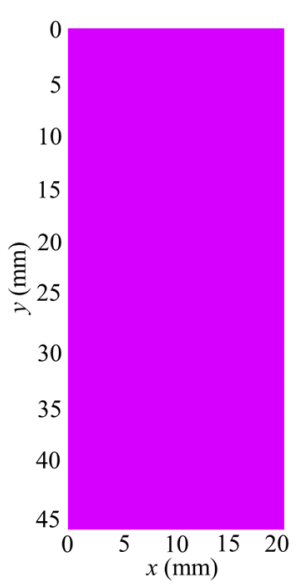

(a)

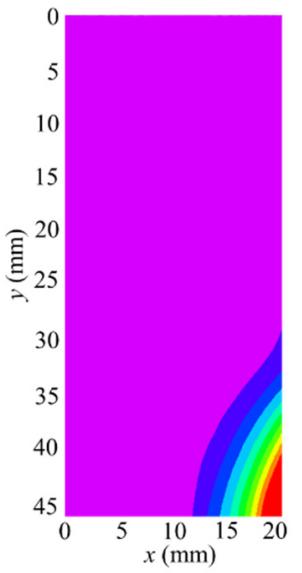

(b)

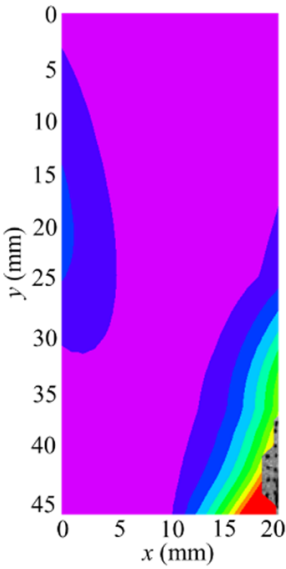

(c)

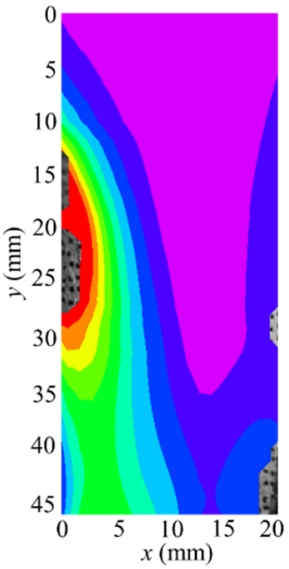

(d)

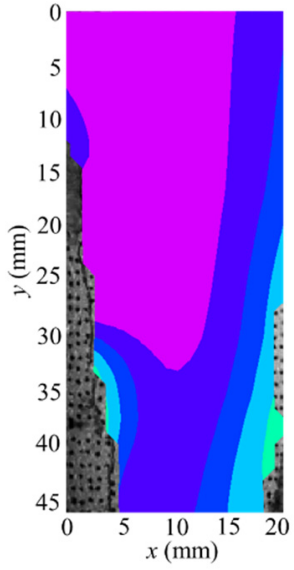

(e)

$\begin{array}{lllllllllll}0.00 & 5.60 & 11.2 & 16.8 & 22.4 & 28.0 & 33.6 & 39.2 & 44.8 & 50.4 & 56.0\end{array}$ $\times 10^{-3}$

Figure 14. The principal strain fields corresponding to point (a-e) under different loading stages in Figure 13.

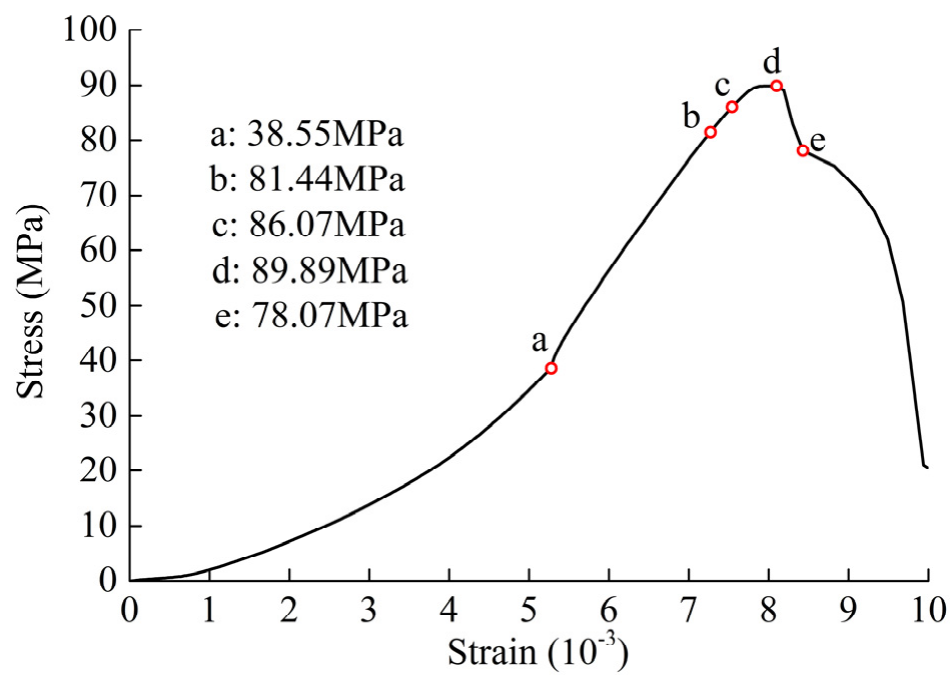

Figure 15. The stress-strain curve and five key stress points of specimen D10.

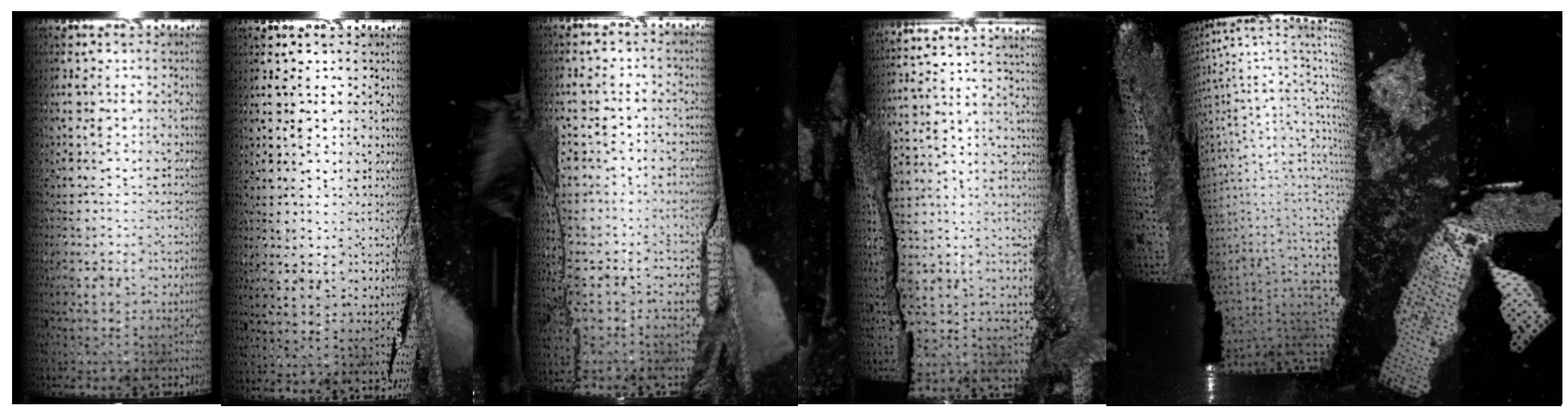

Figure 16. Image of the failure process of specimen D10. 


\section{Conclusions}

(1) The SUCS increases linearly with increasing static pre-stress when the dynamic loading rate ranges from $2 \times 10^{-4}$ to $2 \times 10^{-3} \mathrm{~s}^{-1}$. In addition, the higher the dynamic strain rate, the greater the differences in SUCS under different static pre-stresses.

(2) When the static pre-stress is less than $40-50 \%$ of the UCS, both SUCS and elastic modulus are logarithmically increased with the dynamic loading rate. The SUCS is independent of the dynamic loading rate when the static pre-stress exceeds $60-70 \%$ of the UCS.

(3) For the same dynamic loading rate, the released elastic energy density decreases linearly as the static pre-stress increases, and the dissipated energy density increases. Under low static pre-stress ( $40 \%$ of the UCS) and a high dynamic loading rate $\left(2 \times 10^{-2} \mathrm{~s}^{-1}\right)$, the released elastic energy density of specimen is high $\left(257 \mathrm{~kJ} / \mathrm{m}^{3}\right)$, while the dissipated energy density is low $\left(37.5 \mathrm{~kJ} / \mathrm{m}^{3}\right)$, which may lead to a greater hazard of rock bursts.

(4) More cracks, rock fragments, fine particles and even ejected powder can be observed at a higher dynamic loading rate. Failure mode is transitioned from an axial tensile failure to a shear failure. However, the failure modes of different static pre-stresses are basically the same under the same dynamic loading rate.

(5) Strain localization can be used to identify the crack initiation and propagation processes. The failure mode is closely related to the strain localization zone. The onset of strain localization tends to occur earlier (from post-peak to the peak stress) with the increases in dynamic loading rate, indicating that the strain localization has a significant rate dependence.

Author Contributions: W.C. provided methodology and funding; C.Q. and H.G. contributed to the experimental operation; K.Z. analyzed data and wrote the paper; W.Z. and W.C. reviewed the final paper and made important suggestions and recommendations for paper revision. All authors have read and agreed to the published version of the manuscript.

Funding: This research was funded by the National Natural Science Foundation of China (grant no. 51991393) and the National Natural Science Foundation of China (grant no. 52079134).

Institutional Review Board Statement: Not applicable.

Informed Consent Statement: Not applicable.

Data Availability Statement: The data that support the findings of this study are available from the corresponding author upon request.

Acknowledgments: Special thanks are extended to the Zhaolou coal mine for providing raw rock samples.

Conflicts of Interest: The authors declare that there are no conflicts of interest regarding the publication of this paper.

\section{References}

1. Mazaira, A.; Konicek, P. Intense rockburst impacts in deep underground construction and their prevention. Can. GeoTech. J. 2015, 52, 1426-1439. [CrossRef]

2. Cao, A.Y.; Jing, G.C.; Ding, Y.L.; Liu, S. Mining-induced static and dynamic loading rate effect on rock damage and acoustic emission characteristic under uniaxial compression. Saf. Sci. 2019, 116, 86-96. [CrossRef]

3. Iannacchione, A.T.; Tadolini, S.C. Occurrence, predication, and control of coal burst events in the US. Int. J. Min. Sci. Technol. 2016, 26, 39-46. [CrossRef]

4. Mark, C. Coal bursts in the deep longwall mines of the United States. Int. J. Coal. Sci. Technol. 2016, 3, 1-9. [CrossRef]

5. Hebblewhite, B.; Galvin, J. A review of the geomechanics aspects of a double fatality coal burst at Austar colliery in NSW, Australia in April 2014. Int. J. Min. Sci. Technol. 2017, 27, 3-7. [CrossRef]

6. Lasocki, S.; Idziak, A. Dominant directions of epicentre distribution of regional mining induced seismicity series in Upper Silesian Coal Basin in Poland. Pure Appl. Geophys. 1998, 153, 21-40. [CrossRef]

7. Leśniak, A.; Isakow, Z. Space-time clustering of seismic events and hazard assessment in the Zabrze-Bielszowice coal mine, Poland. Int. J. Rock Mech. Min. Sci. 2009, 46, 918-928. [CrossRef]

8. Batugin, A. A proposed classification of the Earth's crustal areas by the level of geodynamic threat. Geod. Geodyn. 2021, 12, 21-30. [CrossRef] 
9. Konicek, P.; Schreiber, J. Heavy rockbursts due to longwall mining near protective pillars: A case study. Int. J. Min. Sci. Technol. 2018, 28, 799-805. [CrossRef]

10. Konicek, P.; Schreiber, J. Rockburst prevention via destress blasting of competent roof rocks in hard coal longwall mining. J. South Afr. Inst. Min. Metall. 2018, 118, 235-242. [CrossRef]

11. Cao, J.R.; Dou, L.M.; Zhu, G.G.; He, J.; Wang, S.C.; Zhou, K.Y. Mechanisms of Rock Burst in Horizontal Section Mining of a Steeply Inclined Extra-Thick Coal Seam and Prevention Technology. Energies 2020, 13, 6043. [CrossRef]

12. Driad-Lebeau, L.; Lahaie, F.; Al Heib, M.; Josien, J.P.; Bigarre, P.; Noirel, J.F. Seismic and geotechnical investigations following a rockburst in a complex French mining district. Int. J. Coal. Geol. 2005, 64, 66-78. [CrossRef]

13. Lu, C.P.; Liu, G.J.; Liu, Y.; Zhang, N.; Xue, J.H.; Zhang, L. Microseismic multi-parameter characteristics of rockburst hazard induced by hard roof fall and high stress concentration. Int. J. Rock Mech. Min. Sci. 2015, 76, 18-32. [CrossRef]

14. Wang, S.L.; Hao, S.P.; Chen, Y.; Bai, J.B.; Wang, X.Y.; Xu, Y. Numerical investigation of coal pillar failure under simultaneous static and dynamic loading. Int. J. Rock Mech. Min. Sci. 2016, 84, 59-68. [CrossRef]

15. Mcgarr, A. Energy budgets of mining-induced earthquakes and their interactions with nearby stopes. Int. J. Rock Mech. Min. Sci. 2000, 37, 437-443. [CrossRef]

16. Mansurov, V.A. Prediction of rockbursts by analysis of induced seismicity data. Int. J. Rock Mech. Min. Sci. 2001, 38, 893-901. [CrossRef]

17. Dubinski, J.; Mutke, G. Characteristics of mining tremors within the near-wave field zone. Pure Appl. Geophys. 1996, 147, $249-261$. [CrossRef]

18. Bukowska, M. The probability of rockburst occurrence in the Upper Silesian Coal Basin area dependent on natural mining conditions. J. Min. Sci. 2006, 42, 570-577. [CrossRef]

19. He, J.; Dou, L.; Gong, S.; Li, J.; Ma, Z. Rock burst assessment and prediction by dynamic and static stress analysis based on micro-seismic monitoring. Int. J. Rock Mech. Min. Sci. 2017, 93, 46-53. [CrossRef]

20. Konicek, P.; Waclawik, P. Stress changes and seismicity monitoring of hard coal longwall mining in high rockburst risk areas. Tunn. Undergr. Sp. Tech. 2018, 81, 237-251. [CrossRef]

21. Wang, Q.X.; Wang, H.; Qi, Z.Q. An application of nonlinear fuzzy analytic hierarchy process in safety evaluation of coal mine. Saf. Sci. 2016, 86, 78-87. [CrossRef]

22. Hirata, A.; Kameoka, Y.; Hirano, T. Safety management based on detection of possible rock bursts by AE monitoring during tunnel excavation. Rock Mech. Rock Eng. 2007, 40, 563-576. [CrossRef]

23. Wojtecki, O.; Mendecki, M.J.; Zuberek, W.M. Determination of Destress Blasting Effectiveness Using Seismic Source Parameters. Rock Mech. Rock Eng. 2017, 50, 3233-3244. [CrossRef]

24. Holub, K.; Rusajova, J.; Holecko, J. Particle velocity generated by rockburst during exploitation of the longwall and its impact on the workings. Int. J. Rock Mech. Min. Sci. 2011, 48, 942-949. [CrossRef]

25. Gibbons, S.J.; Ringdal, F. The detection of low magnitude seismic events using array-based waveform correlation. Geophys. J. Int. 2006, 165, 149-166. [CrossRef]

26. Li, X.B.; Gong, F.Q.; Tao, M.; Dong, L.J.; Du, K.; Ma, C.D.; Zhou, Z.L.; Yin, T.B. Failure mechanism and coupled static-dynamic loading theory in deep hard rock mining: A review. J. Rock. Mech. Geotec. Eng. 2017, 9, 767-782. [CrossRef]

27. Mutke, G.; Dubiński, J.; Lurka, A. New criteria to assess seismic and rock burst hazard in coal mines. Arch. Min. Sci. 2015, 60, 743-760.

28. Cai, M.; Kaiser, P.K.; Suorineni, F.; Su, K. A study on the dynamic behavior of the Meuse/Hhaute-Marne argillite. Phys. Chem. Earth 2007, 32, 907-916. [CrossRef]

29. He, J.; Dou, L.M.; Cai, W.; Li, Z.L.; Ding, Y.L. In situ test study of characteristics of coal mining dynamic load. Shock. Vib. 2015, 2015, 121053. [CrossRef]

30. Wang, Y.; Li, X.; Zheng, B. Stress-strain behavior of soil-rock mixture at medium strain rates -response to seismic dynamic loading. Soil Dyn. Earthq. Eng. 2017, 93, 7-17. [CrossRef]

31. Li, X.B.; Zhou, Z.L.; Zhao, F.J.; Zuo, Y.J.; Ma, C.D.; Ye, Z.Y.; Hong, L. Mechanical properties of rock under coupled static-dynamic loads. J. Rock. Mech. Geotec. Eng. 2009, 1, 41-47. [CrossRef]

32. Zhou, Z.L.; Cai, X.; Li, X.B.; Cao, W.Z.; Du, X.M. Dynamic response and energy evolution of sandstone under coupled staticdynamic compression: Insights from experimental study into deep rock engineering applications. Rock Mech. Rock Eng. 2020, 53, 1305-1331. [CrossRef]

33. Feng, J.J.; Wang, E.Y.; Chen, X.; Ding, H.C. Energy dissipation rate: An indicator of coal deformation and failure under static and dynamic compressive loads. Int. J. Min. Sci. Technol. 2018, 28, 397-406. [CrossRef]

34. Dai, F.; Xu, Y.; Zhao, T.; Xu, N.W.; Liu, Y. Loading-rate-dependent progressive fracturing of cracked chevron-notched Brazilian disc specimens in split Hopkinson pressure bar tests. Int. J. Rock Mech. Min. Sci. 2016, 88, 49-60. [CrossRef]

35. Feng, P.; Dai, F.; Liu, Y.; Xu, N.W.; Du, H. Coupled Effects of Static-Dynamic Strain Rates on the Mechanical and Fracturing Behaviors of Rock-like Specimens Containing Two Unparallel Fissures. Eng. Fract. Mech. 2018, 207, 237-253. [CrossRef]

36. Dou, L.M.; He, J.; Cao, A.Y.; Gong, S.Y.; Cai, W. Rock burst prevention methods based on theory of dynamic and static combined load induced in coal mine. J. China Coal Soc. 2015, 40, 1469-1476.

37. Lyu, P.; Chen, X.H.; Chen, G.B.; Qiu, L. Experimental study on dynamic mechanical responses of coal specimens under the combined dynamic-static loading. Arab. J. Geosci. 2020, 13, 935. [CrossRef] 
38. Zhao, Y.X.; Liu, S.M.; Zhao, G.F.; Elsworth, D.; Jiang, Y.D.; Han, J.L. Failure mechanisms in coal: Dependence on strain rate and microstructure. J. Geophys. Res. Solid Earth. 2014, 119, 6924-6935. [CrossRef]

39. Liang, C.Y.; Wu, S.R.; Li, X.; Xin, P. Effects of strain rate on fracture characteristics and mesoscopic failure mechanisms of granite. Int. J. Rock Mech. Min. Sci. 2015, 76, 146-154. [CrossRef]

40. Li, S.G.; Du, X.H.; Zhao, P.X.; Xiao, P.; Lin, H.F.; Shuang, H.Q. Experimental study on crack evolution characteristics of rock-like materials under different strain rates. J. Geophys. Eng. 2018, 15, 2071-2078.

41. Kranz, R.L. Crack growth and development during creep of Barre granite. Int. J. Rock Mech. Min. Sci. Geomech. Abstr. 1979, 16, 23-35. [CrossRef]

42. Braz, D.; Barroso, R.C.; Lopes, R.T.; Motta, L.M.G. Crack detection in asphaltic mixtures by computed tomography. NDT E Int. 2011, 44, 195-201. [CrossRef]

43. Frid, V. Calculation of electromagnetic radiation criterion for rock burst hazard forecast in coal mines. Pure Appl. Geophys. 2001, 158, 931-944. [CrossRef]

44. Wu, L.; Liu, S.J.; Wu, Y.H.; Wu, H.P. Changes in IR with rock deformation. Int. J. Rock Mech. Min. Sci. 2002, 39, 825-831. [CrossRef]

45. Li, D.Y.; Gao, F.H.; Han, Z.Y.; Zhu, Q.Q. Experimental evaluation on rock failure mechanism with combined flaws in a connected geometry under coupled static-dynamic loads. Soil. Dyn. Earthq. Eng. 2020, 132, 106088. [CrossRef]

46. Lin, Q.; Labuz, J.F. Fracture of sandstone characterized by digital image correlation. Int. J. Rock Mech. Min. Sci. 2013, 60, 235-245. [CrossRef]

47. Dong, W.; Wu, Z.M.; Zhou, X.M.; Wang, N.; Kastiukas, G. An experimental study on crack propagation at rock-concrete interface using digital image correlation technique. Eng. Fract. Mech. 2017, 171, 50-63. [CrossRef]

48. Zhao, W.S.; Zhong, K.; Chen, W.Z. A Fiber Bragg Grating Borehole Deformation Sensor for Stress Measurement in Coal Mine Rock. Sensors 2020, 20, 3267. [CrossRef]

49. Amaguchi, I. Speckle displacement and decorrelation in the diffraction and image fields for small object deformation. Opt. Acta 1981, 28, 1359-1376. [CrossRef]

50. Vardar, O.; Zhang, C.G.; Canbulat, I.; Hebblewhite, B. A semi-quantitative coal burst risk classification system. Int. J. Min. Sci. Technol. 2018, 28, 721-727. [CrossRef]

51. Xie, H.P.; Li, L.Y.; Peng, R.D.; Ju, Y. Energy analysis and criteria for structural failure of rocks. J. Rock. Mech. Geotec. Eng. 2009, 1, 11-20. [CrossRef]

52. Peng, R.D.; Ju, Y.; Wang, J.G.; Xie, H.P.; Gao, F.; Mao, L.T. Energy dissipation and release during coal failure under conventional triaxial compression. Rock Mech. Rock Eng. 2015, 48, 509-526. [CrossRef]

53. Song, Y.M.; Xing, T.Z.; Deng, L.L.; Zhao, Z.X. Experimental study on rock deformation field evolution under different loading rates. Rock Soil Mech. 2017, 38, 2773-2779.

54. Yang, S.J.; Zeng, S.; Wang, H. Experimental analysis on mechanical effects of loading rates on limestone. Chin. J. Geotech. Eng. 2005, 27, 786-788.

55. Liang, W.G.; Zhao, Y.S.; Xu, S.G.; Dusseault, M.B. Effect of strain rate on the mechanical properties of salt rock. Int. J. Rock Mech. Min. Sci. 2011, 48, 161-167. [CrossRef] 